\title{
SPORTS INFLUENCE ON THE FORMATION OF PERSONAL DEFORMATIONS
}

\author{
Petr RYSKIN ${ }^{1 *}$, Igor SEMENET ${ }^{2}$, Irina VASHLIAEVA ${ }^{1}$, Natalia SHURALEVA ${ }^{1}$ \\ ${ }^{1}$ Ural State University of Economics, Ekaterinburg, Russia \\ ${ }^{2}$ Slavonic University, Republic of Moldova \\ *Corresponding author: unir-2019@mai.ru
}

DOI: $10.35189 /$ iphm.icpesk.2019.42

\begin{abstract}
One of the urgent problems of training professional athletes is the creation of an effective method for diagnosing professional deformations. Some authors are confident that one of the most effective ways to correct professional deformations is associated with an impact on the athlete's self-esteem. From this, we can conclude that the self-assessment can be used to diagnose professional deformations. Among the most frequently encountered professional deformations of professional athletes are neurosis and emotional burnout, which lead to various behavioural deviations and corresponding disruptions in the training process. The aim of the study is to clarify the methodological aspects of diagnosing professional deformations of athletes in the context of their self-esteem. The key parameters of the methodology are survey technologies for detecting neurosis and emotional burnout. The proposed technique comprehensively summarises the questionnaires for identifying personal neuroticism and psychological burnout. The study was conducted on the basis of testing 74 participants with professional sports experience. The results of the study revealed a fairly high level of neuroticism, the average level of emotional burnout developing against the background of high self-esteem and high expectations of athletic performance. Extreme conditions of sports activities lead to overloading and overstraining the athlete's body, which is a favourable basis for the emergence of significant personal deformations, such as emotional burnout and neurotisation. These findings are of significant practical importance, since they allow the formation of corrective behavioural programs during periods of active training and competition.
\end{abstract}

Keywords: professional deformations, self-esteem, neurotisation, emotional burnout, professional sports.

\section{Introduction}

The personality structure of an athlete is impregnated with features of the sport due to sports specialisation. Therefore, physical activity, depending on the requirements of a particular sport, completely develops certain psychological properties and personality traits of the athlete.

In the works of Eysenck (1991) or Kovalev and Myasishchev (1960), the personality structure includes orientation, temperament, character, abilities and self-regulation. In the works of Serova (2007), separate components are distinguished in the structure of the athlete's professional qualities. The first component is a substructure at the level of nerve processes (mobility, dynamism, balance of excitation and inhibition processes). The second component is a substructure at the level of mental processes. The third component is the substructure at the level of orientation of the personality and socially conditioned relationships. The strength of the nervous processes determines the endurance of the athlete's nervous system under the influence of strong or prolonged stimuli. In sports associated with long monotonous work, a strong nervous system is an indicator of performance.

In sports activities, the strength of the nervous system is manifested in the substructure at the level of nervous processes by the persistence of emotional states in competitions, regardless of the state of fitness and the objectivity of the assessment of their capabilities relative to future competitions.

Mobility of nervous processes is a condition for the development of the ability to quickly reorganize actions when changing tactical situations, to change the pace, rhythm and tactics of work. The athlete's self-esteem is the basis for the development of sports activities. The processes of self-esteem accompany the periods of formation, development and improvement of the athlete and are one of the important means of achieving a sports result. In addition, self-esteem is among the basic indicators of the athlete's activity, the enhancement of personal capabilities affecting their level of claims. The specificity of understanding the adequacy of self-esteem in sports activities lies in the fact that athletes steadily observe some of their overestimation. In the interest of improving the efficiency of athlete training, it is necessary to purposefully shape their ability to more adequately assess their readiness for the upcoming competition. At earlier stages, it is necessary to give beginner athletes tasks on selfassessment of the accuracy of specific exercises, manifestations of individual physical qualities and the degree of perfection of the movement technique. (Razinkin, 2015)

Self-esteem is a significant component of self-awareness, since it plays the role of an activity regulator, ensuring its best adaptation to changing living conditions. The study of self-esteem in the field of sports is associated with its both direct and indirect influence on success. Self-esteem can contribute to the development of 
various deformations of the personality, which in turn hinder the achievement of sports results (Bosenko \& Berilova, 2015). Therefore, by influencing self-esteem, it is possible to prevent the occurrence of these deformations.

Changes in self-esteem can be caused by neuroticism and emotional burnout, which lead to exhaustion and deviations in the behaviour of an athlete, and this undermines mental health and makes it impossible to win (Vysochina, 2010).

According to modern concepts, self-awareness is a complex psychological process, the essence of which consists in the perception by the individual of many "images" of him/herself in various situations of activity and behaviour, in interaction with other people and in combining these images into a single holistic education - in the presentation of one's "I am" as a different subject. Structurally, self-consciousness is a unity of three sides - the cognitive (self-knowledge), emotional-axiological (self-relation) and effective-willed, regulatory (self-regulation) ones. Various aspects of the problem of self-awareness were studied; however, small attention was paid to the particularities of the self-esteem formation in connection with the manifestation of personal deformations in sports activities. Therefore, we believe that identifying the relationship of self-esteem with deformations of the personality such as emotional burnout and neuroticism will help to find ways to improve athletic success.

The aim of the study was to analyse the characteristics of the formation of the athlete's personality (selfesteem, neuroticism and emotional burnout) under the influence of sports activities.

\section{Material and Methods}

The sample of subjects was composed of male and female athletes aged 20 to 25 years, who were divided into two groups. The first group $(\mathrm{n}=12)$ included representatives of various sports: athletics, skiing, billiards, wrestling and mountaineering, with second-degree adult qualifications up to the International Master of Sports. The second group $(n=16)$ was made up of representatives of team sports, their qualifications varying from the second-degree adult qualification to the candidate for the Master of Sports.

The following psycho-diagnostic methods were used: an integral self-assessment of the personality: "Who am I in this world?" and the level of personal neuroticism (Boyko, 1999) (evaluation parameters are shown in Figure 1); method of determining mental "burnout" (Orel \& Rukavishnikov, 2001) (evaluation parameters are shown in Figure 2).

\section{The method of integral self-assessment of the personality: "Who am I in this world?"}

In front of the subject, there are 10 seven-point lines denoting the following qualities of a person: health, intelligence, kindness, honesty, sociability, integrity, sincerity, courage, attractiveness, happiness. On the left side, there are the qualities of people with the lowest grades (sick, deceitful, coward, etc.), and on the right side, the highest grades (the kindest, smartest, healthier, etc.). Next, there is a self-test on the above parameters.

Subsequently, the total points for all 10 parameters are calculated. Depending on the score, the self-assessment indicator can be as follows:

- clearly high self-esteem - 60-70 points;

- tendency to overestimate $-46-59$ points;

- adequate self-esteem - about 40 points $( \pm 5)$;

- tendency to understate - 34-21 points;

- clearly low self-esteem - 20-10 points.

\section{Results and Discussion}

Self-esteem is a sustainable personal formation on the basis of which a person builds their attitude towards themselves and those around them, and also determines the characteristics of an athlete's behaviour in various situations. Athletes have a tendency to overrate self-esteem, which reflects their desire for success in various activities, their self-reliance and contributes to the success of the activity. With regard to their own mistakes, athletes with such a level of self-esteem often prefer not to correct them and forget. Their mistakes are considered random, caused by extraneous factors, while others' mistakes are natural, self-evident, and athletes are relatively indifferent to them.

Extreme conditions of sports activities lead to overloading and overstraining the athlete's body, which is a favourable basis for the emergence of personal deformations such as emotional burnout and neurotisation. The 
studied athletes showed an average level of neurosis in the first group and a low level of neurotisation in the second group (Figure 1). These results indicate emotional stability, a positive background of experiences, peace and optimism, initiative, independence, social courage, self-esteem and ease of communication. The average level of neuroticism suggests that athletes in the most intense, overloaded periods of their activity are subject to mental exhaustion. Signs of irritability, anxiety, aggressiveness, depression, hypersensitivity to the estimates of others are also possible. Sometimes, there is a reluctance to engage in sports activities, which can manifest in skipping training.

According to the study, the values of personal distance indicators were low. Athletes may experience social maladjustment, which is manifested in some reluctance to contact people, irritability and intolerance in situations of communication, which causes a negative attitude towards people, reduced contact with others and, as a result, indifference to sports activities (Figure 2 and Figure 3).

20. The most difficult struggle for me is fighting with myself.

19. At times, it seems to me that my head is slower than usual.

15. I find it difficult to concentrate on a job or at work.

14. Life for me is almost always associated with stress.

13. I try to meet less often with my acquaintances and friends.

12. I am constantly worried about something.

11. Most of the time I am dissatisfied with life.

10. Sometimes I am so excited that it prevents me from falling asleep.

9. Usually work costs me a lot of stress.

8. I had periods when, because of my excitement, I lost sleep.

7. Almost every day something happens that scares me.

5. Two or three times a week at night, nightmares torment me.

3. Once a week or more often I am very excited or agitated.

2. I rarely suffocate, and I do not have a strong heartbeat. 1. In various parts of my body, I often feel burning, pricking, goosebumps, numbness.

18. I often indulge in sad reflections.

17. I believe in the future.

16. I get very tired for the day.

6. Recently I feel worse than ever.

4. My head hurts often.

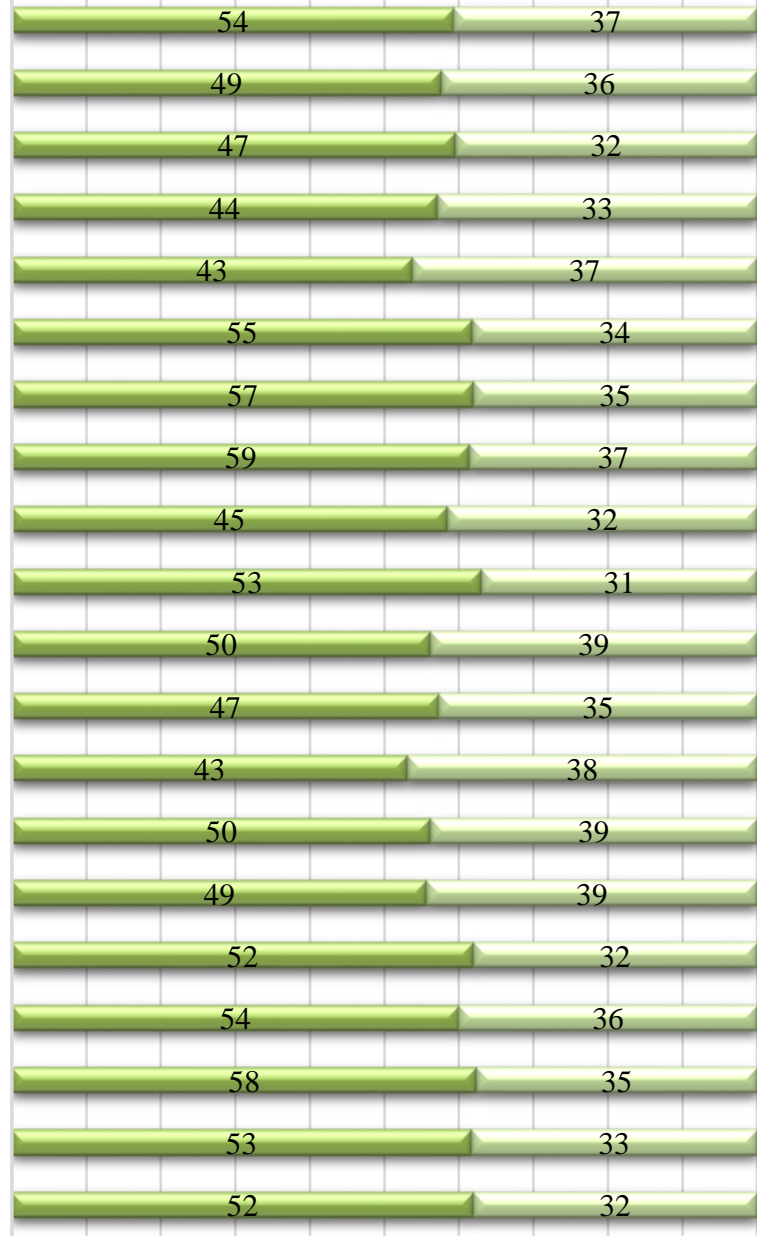

$\begin{array}{lllllllllll}0 \% & 10 \% & 20 \% & 30 \% & 40 \% & 50 \% & 60 \% & 70 \% & 80 \% & 90 \% & 100 \%\end{array}$

$\square$ The first group $(\mathrm{n}=12) \quad \square$ The second group $(\mathrm{n}=16)$

Figure 1. Results of the personal neurotisation study of athletes in the context of special questions, $\%$ 
International Proceedings of Human Motricity/ ICPESK 2019

Supplementary Issue of Discobolul - Physical Education, Sport and Kinetotherapy Journal, 2019

20. Going to work in the morning, I do not feel refreshed and rested.

19. It is important for me to succeed at work.

18. It is difficult for me to establish or maintain close contacts with colleagues.

17. I feel that I receive little satisfaction from the successes achieved at work.

16. I feel exhausted and overwhelmed after work.

15. I think that I was wrong in choosing my profession

14. I am emotionally tired at work.

13. The incompetence of my colleagues or students annoys me.

12. I am not satisfied with the profession I have chosen

11. I get tired of the human problems that I face at work.

10. I think my work is important.

9. I feel that working with people is exhausting me.

8. My work does not bring me satisfaction

7. I work with a lot of stress.

6. I think that if a good opportunity presented itself, I would change my place of work.

5. I am tormented by insomnia

4. I feel that I have no emotional strength to delve into other people's problems.

3. It bothers me what colleagues think about my work.

2. I think that I work only because I need to work somewhere.

1. I get easily annoyed.
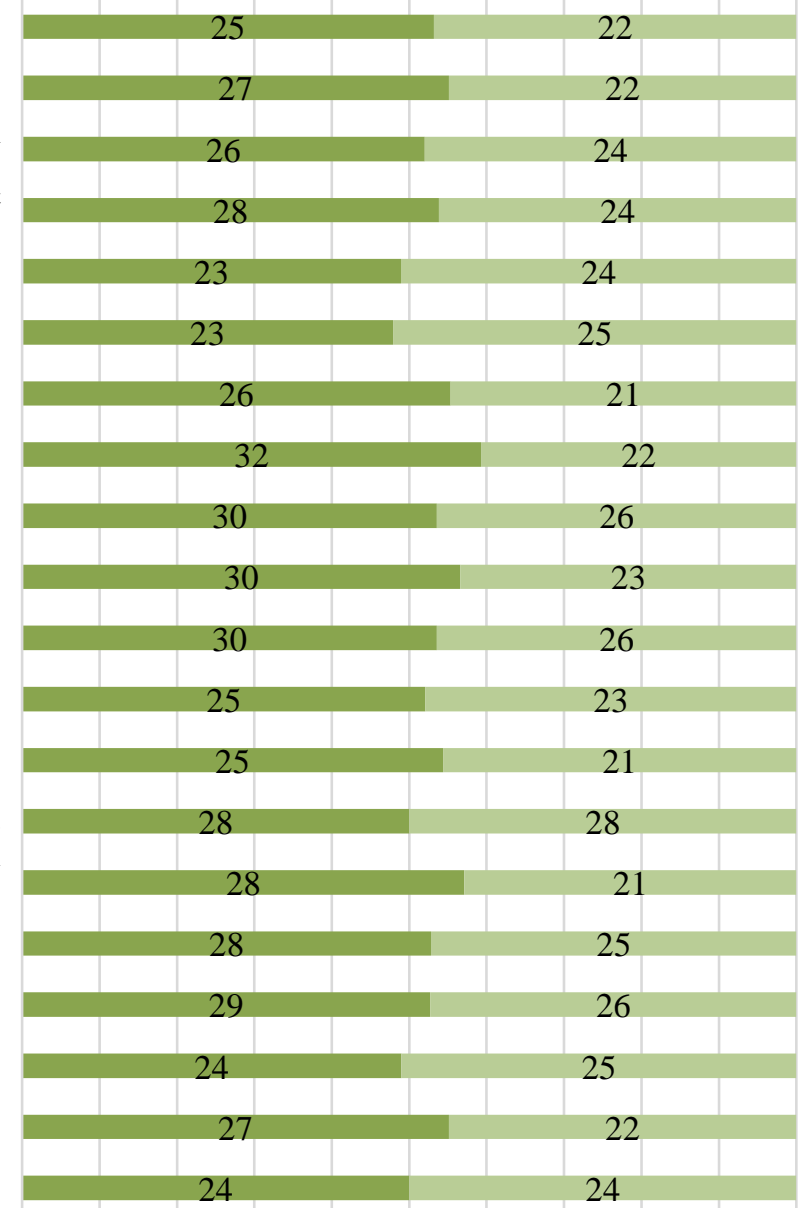

$\begin{array}{lllllllllll}0 \% & 10 \% & 20 \% & 30 \% & 40 \% & 50 \% & 60 \% & 70 \% & 80 \% & 90 \% & 100 \%\end{array}$

$\square$ The first group $(\mathrm{n}=12) \quad \square$ The second group $(\mathrm{n}=16)$

Figure 2. Results of the personal distance study of athletes in the context of special questions, \% 


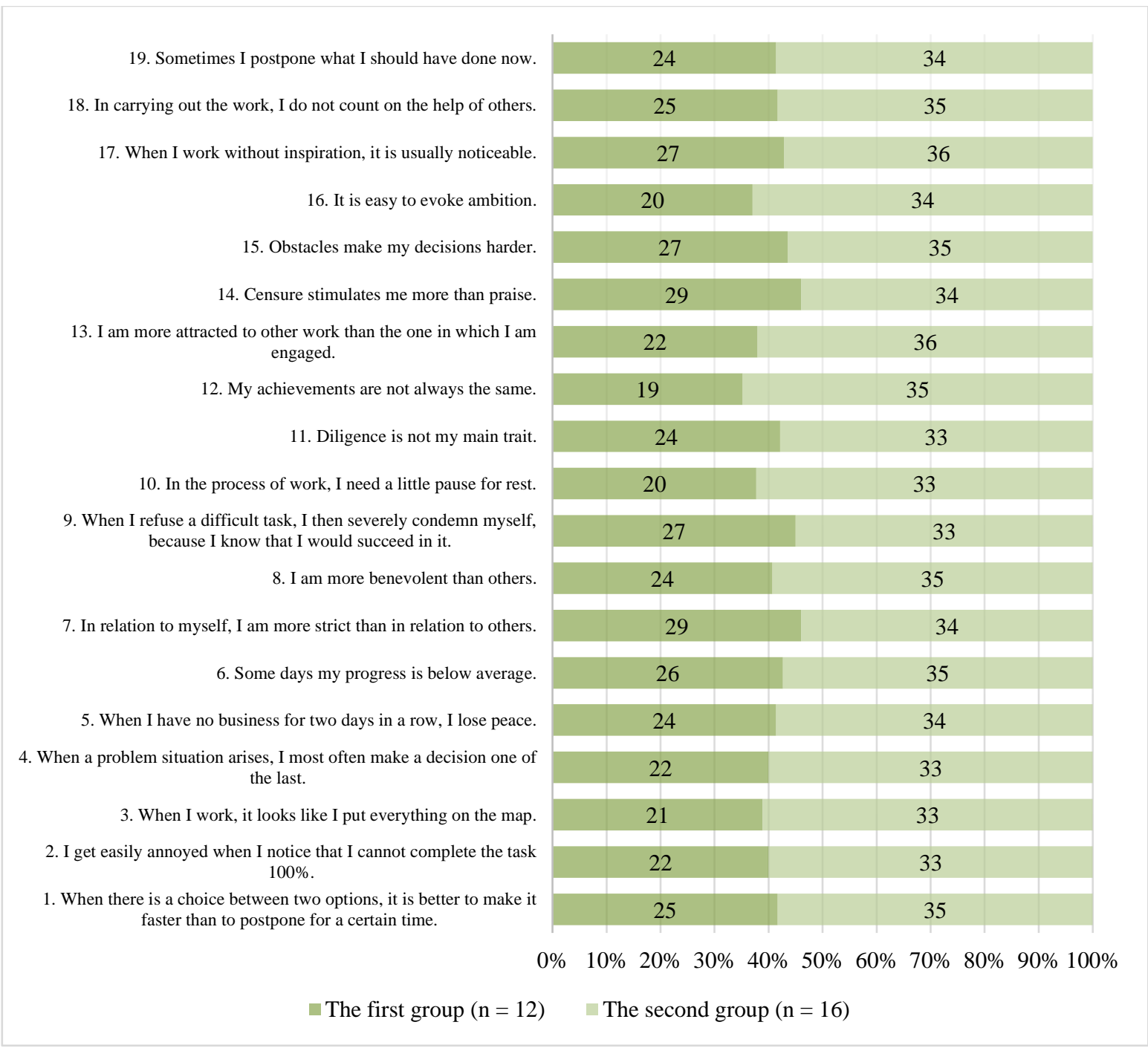

Figure 3. Results of the personal motivation study of athletes in the context of special questions, \%

High values of professional motivation indicate that athletes have a high level of enthusiasm for the activities with an altruistic content. This in turn can lead to dissatisfaction with sports activities, self as a professional and team relationships, reducing the need for achievements.

In the first group, as well as in the second group, there are subjects who have both adequate and overestimated self-esteem. Athletes with such indicators are characterised by arrogance, tactlessness, overestimation of their capabilities and underestimation of others. The lowest rates are in the first and second samples, respectively, which reflects an adequate self-assessment. Both samples have a normal distribution. Significant differences between the two samples of athletes in terms of self-esteem were not identified. According to other researchers, the optimal situation determining the success of sports activities is adequate or not very high self-esteem.

To identify the relationship between the self-esteem of athletes and the indicators of personal deformations (neurotic, personal distance, professional motivation), an analysis was conducted that revealed the reverse relationship between self-assessment indicators and the level of mental burnout, namely components such as psycho-emotional exhaustion and personal distance. People with low self-esteem are more prone to mental and physical exhaustion, the formation of indifference to their professional activities, compared to individuals with high and adequate self-esteem.

\section{Conclusion}

During the study, athletes showed a tendency to overrating self-esteem, a low level of neuroticism and average values of the two psycho-emotional indicators, exhaustion and personal distance. They also found extremely high 
rates of professional motivation. These indicators show a high level of control over one's own emotions when experiencing high physical and psychological stress. In general, the study confirms the results obtained during similar experiments. In addition to the existing results, the need to identify personal regulators can be noted. For most athletes, self-assessment is the regulator. The study allowed to trace the characteristics of the manifestation of personal deformations (neuroticism and emotional burnout), which is of great practical importance for the formation of the personality of athletes. The study results can be used in the training of athletes in the national team and the national reserve team in various sports. The diagnostic data of self-assessment, personal neuroticism and emotional burnout are introduced into the educational process of student athletes, which has made it possible to more effectively implement the adaptation process to conduct classes.

\section{References}

Bosenko, Yu. M., \& Berilova, E. I. (2015). Personal and cognitive factors of high class athletes' resistance to stress (In Russian). Bulletin of the Kostroma State University, Series Pedagogy, Psychology, Sociokinetics, 2l(2).

Boyko, V. V. (1999). Methods of diagnosing the level of emotional burnout. Practical psychodiagnostics (In Russian). Samara.

Eysenck, H. J. (1991). Dimensions of personality: 16, 5 or 3? Criteria for a taxonomic paradigm. Personality and Individual Differences, 12(8), 773-790. https://doi.org/10.1016/0191-8869(91)90144-Z

Kovalev, A. G., \& Myasishchev, V. N. (1960). Psychological features of a person (In Russian). Leningrad: LSU.

Orel, V. E., \& Rukavishnikov, A. A. (2001). The phenomenon of "burnout" as a manifestation of the impact of professional activity on the individual. Psychology of the Subject of Professional Activity (Collection of scientific papers).

Razinkin, S. M., Petrova, V. V., Artamonova, I. A., \& Fomkin, P. A. (2015). Development and substantiation of the criterial apparatus for assessing the level of the athlete's psychophysical health (In Russian). Journal of Neurology, Psychiatry and Neurosurgery, 5-6, 36-44.

Serova, L. K. (2007). Psychology of the personality of the athlete (In Russian). Moscow: Soviet Sport, 116, 1.

Vysochina, N. (2010). The influence of self-esteem on the emotional state of an athlete as personality (In Russian). Pedagogy, Psychology and Biomedical Problems of Physical Education and Sport, 3. 